University of Wollongong

Research Online

Faculty of Engineering and Information

Faculty of Engineering and Information

Sciences - Papers: Part A

Sciences

$1-1-2013$

\title{
Modification of a polyamide reverse osmosis membrane by heat treatment for enhanced fouling resistance
}

Takahiro Fujioka

University of Wollongong, tf385@uowmail.edu.au

Long D. Nghiem

University of Wollongong, longn@uow.edu.au

Follow this and additional works at: https://ro.uow.edu.au/eispapers

Part of the Engineering Commons, and the Science and Technology Studies Commons

Research Online is the open access institutional repository for the University of Wollongong. For further information contact the UOW Library: research-pubs@uow.edu.au 


\title{
Modification of a polyamide reverse osmosis membrane by heat treatment for enhanced fouling resistance
}

\author{
Abstract \\ The use of heat treatment to improve solute rejection and fouling resistance of a polyamide reverse \\ osmosis (RO) membrane was investigated in this study. Heat treatment was carried out by immersing the \\ membrane samples in Milli-Q water at 70 degrees celcius for a specific duration. Heat treatment reduced \\ the pure water permeability from 4.1 to $2.8 \mathrm{~L} / \mathrm{m} 2$ bar but improved conductivity rejection from 95.5 to \\ 97.0 percent. As a result, a correlation was observed between changes in the two parameters. Marginal \\ changes in the membrane surface characteristics were observed as a result of heat treatment. Heat \\ treatment significantly improved the fouling resistance property of the RO membrane. When the \\ secondary effluent was filtrated at an elevated permeated flux, the virgin RO membrane exhibited 30 \\ percent flux decline while the heat-treated membrane showed only 12 percent flux decline. This is \\ possibly because heat treatment resulted in a denser cross-linked active skin layer, thus reducing the \\ blockage caused by small organic foulants.
}

\section{Keywords}

membrane, enhanced, osmosis, fouling, resistance, reverse, treatment, polyamide, heat, modification

\section{Disciplines}

Engineering | Science and Technology Studies

\section{Publication Details}

Fujioka, T. \& Nghiem, L. D. (2013). Modification of a polyamide reverse osmosis membrane by heat treatment for enhanced fouling resistance. Water Science and Technology: Water Supply, 13 (6), 1553-1559. 


\title{
Modification of a polyamide reverse osmosis membrane by heat treatment for an enhanced fouling resistance
}

\author{
Revised version submitted to \\ Water Science and Technology
}

April 2013

Takahiro Fujioka and Long D. Nghiem *

Strategic Water Infrastructure Laboratory, School of Civil Mining and Environmental

Engineering, The University of Wollongong, NSW 2522, Australia

\footnotetext{
* Corresponding author: Long Duc Nghiem, Email: longn@uow.edu.au, Ph +61 242214590
} 


\begin{abstract}
The use of heat treatment to improve solute rejection and fouling resistance of a polyamide reverse osmosis (RO) membrane was investigated in this study. Heat treatment was carried out by immersing the membrane samples in Milli-Q water at $70{ }^{\circ} \mathrm{C}$ for a specific duration. Heat treatment (24 hours) reduced the pure water permeability from 4.1 to $2.8 \mathrm{~L} / \mathrm{m}^{2} \mathrm{hbar}$ but improved conductivity rejection from 95.5 to $97.0 \%$. As a result, a correlation was observed between changes in the two parameters. Marginal changes in the membrane surface characteristics (i.e. zeta potential, hydrophobicity, chemistry and roughness) were observed as a result of heat treatment. Heat treatment significantly improved the fouling resistance property of the RO membrane. When the secondary effluent was filtrated at an elevated permeated flux, the virgin RO membrane exhibited 30\% flux decline while the heat-treated membrane showed only $12 \%$ flux decline. This is possibly because heat treatment resulted in a denser cross-linked active skin layer, thus reducing the blockage caused by small organic foulants.
\end{abstract}

Keywords: Membrane fouling; modification; reverse osmosis (RO); water reuse. 


\section{Introduction}

Fresh water resources for drinking water have been increasingly insecure in many parts of the world due to prolonged droughts and increased water consumption. Accordingly, water authorities in these regions are considering water reuse and seawater desalination as attractive and viable options to supplement their drinking water supply (Elimelech 2006). In these applications, reverse osmosis (RO) membrane is often employed for removing pathogenic agents, colour, salt and trace organic chemicals (Bellona et al. 2008; Traves et al. 2008; Wintgens et al. 2008). However, impurities that are present in wastewater can cause membrane fouling after a sustained period of operation (Fritzmann et al. 2007; Matin et al. 2011). The development of fouling layer on the membrane surface results in an increase in energy consumption to maintain a constant water production and consequently it leads to frequent chemical cleaning for restoring membrane permeability.

Commercially available RO membranes consist of a thin active polyamide skin layer on top of a porous supporting layer. The permeability, separation performance and fouling susceptibility of RO membranes are exclusively governed by the characteristics of their active skin layer. Thus, numerous previous studies have investigated the development and modification of the active skin layer for better membrane performance (Kang \& Cao 2012). These investigations include the development of polymerisation monomers materials, interfacial polymerisation processes (Lee et al. 2011) and hybrid active skin layers containing inorganic particles (Li \& Wang 2010). Other approaches have also focused on the active skin layer modification using commercial RO membranes. Among them, physical modification approaches include adsorption and coating, while chemical modification approaches are mainly based on hydrophilisation, radical grafting, chemical coupling and plasma polymerisation (Kang \& Cao 2012). In fact, when the active skin layer has higher hydrophilicity and lower negative charge, less membrane fouling occurs due to reduced adsorption of organic matters on membrane surface (Gerard et al. 1998; Bartels et al. 2008). A recent study also reported that the anti-fouling property of RO membranes can be improved by surface hydrophilic modification using plasma polymerisation (Zou et al. 2011). However, the execution of these membrane surface modifications requires manufacturing steps, resulting in additional production costs. 
A recent study by Shintani et al. (2009) applied heat treatment at various air temperatures (40-180 ${ }^{\circ} \mathrm{C}$ ) to polyamide RO membranes and revealed that the heat treatment of over $80{ }^{\circ} \mathrm{C}$ decreased permeate flux of the RO membranes but increased their salt rejections. During the heat treatment, the polyamide RO membranes were heat-treated for only 30 seconds, which may be more economical than the other surface modification techniques. They suggested that a denser active skin layer can be developed with the heat treatment, resulting in less solute passage and less water permeability. However, Shintani et al. (2009) did not investigate the fouling behaviour of the membrane after heat treatment. In fact, to date, no previous studies have reported the improvement of anti-fouling characteristics of RO membranes using the heat treatment.

The aim of this study is to identify the effects of the heat treatment of RO membranes on membrane fouling. A commercial virgin RO membrane was used for the heat treatment. The impact of the heat treatment on fouling development was investigated using secondary effluent. The changes in membrane characteristics by the heat treatment were also evaluated by examining zeta potential, contact angle, pure water permeability and salt rejection.

\section{Materials and methods}

\section{Membranes}

The reverse osmosis membrane ESPA2 was supplied by Hydranautics (Oceanside, CA, USA) as flat sheet membrane samples. This is a low pressure reverse osmosis (LPRO) membrane that possesses a thin polyamide active skin layer supported by a porous polysulfone layer. The ESPA2 membrane has been widely used for water reclamation applications (Fujioka et al. 2012). The maximum operating temperature of the membrane specified by the manufacturer is $45^{\circ} \mathrm{C}$.

\section{Chemicals}

Analytical grade $\mathrm{NaCl}, \mathrm{CaCl}_{2}$ and $\mathrm{NaHCO}_{3}$ were obtained from Ajax Finechem (Taren Point, NSW, Australia). For background electrolytes during rejection tests, a stock solution of each chemical was prepared in Milli-Q water at $2 \mathrm{M}(\mathrm{NaCl})$ and $0.1 \mathrm{M}\left(\mathrm{CaCl}_{2}\right.$ and $\left.\mathrm{NaHCO}_{3}\right)$. 


\section{Membrane filtration system}

A laboratory scale cross flow RO filtration system was used in this study (Figure 1). The membrane sample was held in a stainless steel cross flow cell with an effective area of 40 $\mathrm{cm}^{2}(4 \mathrm{~cm} \times 10 \mathrm{~cm})$ and a channel height of $2 \mathrm{~mm}$. A high pressure pump (HydraCell, Wanner Engineering Inc., Minneapolis, MN, USA) transfers the feed solution from a stainless steel reservoir to the membrane cell. The permeate flow rate and cross flow velocity were controlled by a bypass valve and back-pressure valve (Swagelok, Solon, OH, USA). The permeate flow was monitored using a digital flow meter (FlowCal, GJC Instruments Ltd, Cheshire, UK) which was connected to a personal computer. The concentrate flow was monitored by a rotameter. The feed solution temperature was controlled in the feed reservoir using a stainless steel heat exchanging pipe which was connected to a temperature control unit (Neslab RTE 7, Thermo Scientific Inc., Waltham, MA, USA).

\section{[Figure 1]}

\section{Experimental protocols}

\section{$\underline{\text { Heat treatment }}$}

Prior to the heat treatment, the membrane samples were rinsed with a copious amount of Milli-Q water to remove any preservative chemicals from the membrane surface. They were then immersed in Milli-Q water at $70{ }^{\circ} \mathrm{C}$ for a specified period (3, 24 or 72 hours). The temperature of the Milli-Q solution was controlled using a temperature-controlled water bath (SWV20D, Ratek, Victoria, Australia). Following the heat treatment procedure, the membrane samples were stored in Milli-Q water at $4{ }^{\circ} \mathrm{C}$ in the dark until they were used for experiments.

\section{Filtration experiments}

Prior to each filtration experiment, the membrane sample was compacted at 1,800 kPa using Milli-Q water until the permeate flux has been stabilised. Following the compaction step, the feed solution was conditioned to $20 \mathrm{mM} \mathrm{NaCl}, 1 \mathrm{mM} \mathrm{CaCl}_{2}$ and $1 \mathrm{mM} \mathrm{NaHCO}_{3}$ by adding appropriate volume of stock solution of each chemical. Thereafter, the permeate flux was

adjusted to $20 \mathrm{~L} / \mathrm{m}^{2} \mathrm{~h}$. The filtration system was operated for at least $60 \mathrm{~min}$ before the 
permeate and concentrate were sampled for conductivity analysis. The cross flow velocity and feed temperature in the reservoir were $0.42 \mathrm{~m} / \mathrm{s}$ and $20.0 \pm 0.1^{\circ} \mathrm{C}$, respectively.

Membrane fouling was induced using a secondary treated effluent collected from a sewage treatment plant in Wollongong (New South Wales, Australia). The treatment train of the plant prior to the sampling point included screening, grit removal, sedimentation, activated sludge treatment and clarifier. The wastewater contains a large fraction of low molecular weight organics such as building blocks (300-500 Da) and low molecular weight neutrals (<350 Da) (Fujioka et al. 2013). Each experiment started with the compaction step as described above. Thereafter, feed solution was replaced with the secondary effluent, and the permeate flux was elevated to $30 \mathrm{~L} / \mathrm{m}^{2} \mathrm{~h}$ to induce membrane fouling. The system was then continuously operated for 20 hours maintaining the originally set feed pressure. During the fouling development, the cross flow velocity and feed temperature in the reservoir were also $0.42 \mathrm{~m} / \mathrm{s}$ and $20.0 \pm 0.1{ }^{\circ} \mathrm{C}$, respectively.

\section{Membrane characterisation and analytical techniques}

$\underline{\text { Analytical techniques }}$

Conductivity, $\mathrm{pH}$ and temperature of solutions were measured using an Orion 4-Star Plus pH/conductivity meter (Thermo scientific, USA). Total organic carbon (TOC) concentration was determined using a TOC-V CSH analyser (Shimadzu, Japan).

\section{Zeta potential measurement}

Zeta potential of the membrane surface was analysed using a SurPASS Electrokinetic Analyser (Anton Paar GmbH, Graz, Austria). The Fairbrother-Martin streaming potential method was used to determine the zeta potential of each sample (Elimelech et al. 1994). The background electrolyte solution used in this study was $1 \mathrm{mM} \mathrm{KCl}$. The $\mathrm{pH}$ of the background electrolyte was initially adjusted around $\mathrm{pH} 9$ using $\mathrm{KOH}(1 \mathrm{M})$ solution and it was incrementally decreased to below $\mathrm{pH} 3$ by a titration of $\mathrm{HCl}(1 \mathrm{M})$ solution. The background solution temperature was $25 \pm 1^{\circ} \mathrm{C}$.

\section{Contact angle measurement}

Contact angle of RO membrane surface was measured using a Rame-Hart Goniometer (Model 250, Rame-Hart, Netcong, NJ). The sample was rinsed with Milli-Q water and air- 
dried for over 24 hours prior to the measurement. The contact angle was measured on ten different locations of each membrane sample to obtain the average value and the standard deviation.

\section{Surface chemistry}

Fourier transform infrared spectroscopy (FTIR) spectra were used to analyse functional groups of RO membranes. The FTIR spectrophotometer (IRAffinity-1, Shimazu, Kyoto, Japan) used in this study is equipped with a diamond crystal plate. The active skin layer of membrane samples was fixed on the diamond crystal plate and the spectrum was obtained in the range of $400-4000 \mathrm{~cm}^{-1}$ at $2 \mathrm{~cm}^{-1}$ resolution.

\section{Surface topography}

Membrane surface roughness of the RO membranes was determined using an MFP-3D atomic force microscope (AFM) (Asylum Research, Santa Barbara, CA, USA). The scanning was performed in air in tapping mode using Nanoworld NCHR silicon cantilevers (spring constant of $\sim 40 \mathrm{~N} / \mathrm{m})$. The scanning area was $20 \mu \mathrm{m}$ x $20 \mu \mathrm{m}$.

\section{Results and Discussion}

\section{Membrane characteristics}

After three hours of heat treatment, the membrane permeability decreased from 4.1 to 2.8 $\mathrm{L} / \mathrm{m}^{2} \mathrm{hbar}$ (Figure 2a). No further discernible decrease in the membrane permeability could be observed as the heat treatment duration increased to 24 and 72 hours. On the other hand, heat treatment led to an increase in conductivity rejection (Figure 2b). No further statistically significant increase in conductivity rejection was observed after 3 hours of heat treatment. It is also noteworthy that changes in the membrane permeability and conductivity rejection due to heat treatment appear to be inversely correlated (Figure 3). The effect of the heat treatment reported here is consistent with a previous study by Shintani et al (2009), who investigated the impact of heat treating a polyamide RO membrane at $100^{\circ} \mathrm{C}$ on water permeability. They suggested that heat treatment can result in further cross-linking by inducing reaction between the free amine and carboxylic functional groups within the membrane active polyamide skin layer. The increase in cross-linking results in a denser active skin layer, thus leading to a decrease in permeability and an increase in solute rejection as reported in Figure 2. 


\section{[Figure 2]}

\section{[Figure 3]}

Conductivity rejection by RO membranes can also be governed by electrostatic interactions that occur between charged solutes and the charged membrane surface (Bellona et al. 2004). However, no significant changes in the zeta potential of the membrane surface were observed (Figure 4). The impact of heat treatment on contact angle, which represents membrane surface hydrophobicity, was also insignificant. The membrane remained hydrophilic with contact angle value ranging from 25 - $40^{\circ}$ with or without heat treatment. Provided that these analysis (i.e. zeta potential and contact angle) fundamentally represents the membrane properties of the active skin layer surface, these results indicate that heat treatment affected the internal structure and/or internal membrane properties of the polyamide active skin layer but not the membrane surface properties.

Membrane surface characteristics were further investigated using FTIR and AFM. The bonding structure of the polyamide active skin layer and the polysulfone supporting layer can be found with FTIR spectra of the RO membranes in the range of $1750-750 \mathrm{~cm}^{-1}$. Peaks that are associated with polyamides can be found at 1663, 1609 and $1541 \mathrm{~cm}^{-1}$ that represent C-O and C-N stretching and C-C-N deformation vibration (amide I), N-H deformation vibration and $\mathrm{C}=\mathrm{C}$ ring stretching vibration of aromatic amide, and $\mathrm{N}-\mathrm{H}$ in-place bending and $\mathrm{N}-\mathrm{C}$ stretching vibration of a -CO-NH- group (amide II), respectively (Vrijenhoek et al. 2001; Tang et al. 2007). No discernible changes in these three peaks were observed with and without heat treatment (Figure 5). Heat treatment resulted in a small increase in the membrane surface roughness from $89.0 \mathrm{~nm}$ (virgin membrane) to $119.4 \mathrm{~nm}$ (heat treated for 24 hours). Overall, membrane surface characterisation results reported here suggest that heat treatment did not result in any changes in chemical bonding of the membrane surface. However, there were physical changes in the membrane surface evidence by a small increase in surface roughness which can be attributed to the contraction of the polymeric matrix of the cross linked active skin layer, resulting in an increase in salt rejection.

\section{[Figure 4]}

\section{[Figure 5]}




\section{Resistance to Membrane Fouling}

To assess the membrane fouling propensity, filtration of the secondary effluent was conducted at an elevated permeate flux value of $30 \mathrm{~L} / \mathrm{m}^{2} \mathrm{~h}$ which is 1.5 times higher than that typically used in a full scale RO installation for water reuse application. The permeate flux of the virgin RO membrane dropped by $20 \%$ within the first five hours of filtration and gradually decreased further by about 10\% (Figure 6). In contrast, the permeate flux of the heat-treated (24 hours) ESPA2 membrane exhibited only about 5\% drop within the first two hours of filtration and a total of approximately $12 \%$ decline at the end of the experiment. As a result, fouling caused a considerable reduction of permeability from $4.1 \mathrm{~L} / \mathrm{m}^{2} \mathrm{hbar}$ to 2.9 $\mathrm{L} / \mathrm{m}^{2} \mathrm{hbar}$ for the virgin membrane, while the permeability of the heat-treated membrane revealed a negligible reduction from $2.9 \mathrm{~L} / \mathrm{m}^{2} \mathrm{hbar}$ to $2.6 \mathrm{~L} / \mathrm{m}^{2} \mathrm{hbar}$. In addition to the effect on fouling resistant, heat treatment (24 hours) also slightly increased the rejection of TOC (from 95 to 96\%) and conductivity (from 97.7 to 98.1\%). Overall, it appears that heat treatment reduced permeability but this was offset by improved fouling resistance and separation efficiency.

Membrane fouling of RO membranes using the secondary effluent mainly progresses with the adsorption and deposition of organic matter (Xu et al. 2010). Nevertheless, a fraction of small organics permeates through RO membranes and these small organics include building blocks, and low molecular weight acids and neutrals (Henderson et al. 2010). Some of these small organics may also be trapped within the free-volume hole of the active skin layer, which can lead to a decrease in permeate flux. In general, tighter membranes (e.g. RO membranes) are less susceptible to flux decline than looser membranes (e.g. nanofiltration membranes) (Fujioka et al. 2013). Thus, the denser active skin layer of the heat-treated RO membranes may prevent the penetration of low molecular weight organic foulants into the internal structure of the active skin layer, resulting in the slower fouling development. Although it is beyond the scope of this current study, the measurement of free space of the active skin layer may support this hypothesis.

\section{[Figure 6]}




\section{Conclusions}

Heat treatment of the polyamide RO membrane ESPA2 reduced the pure water permeability but improved the separation efficiency and fouling resistance. On the other hand, the membrane surface characteristics (i.e. zeta potential, hydrophobicity, chemistry and roughness) were not significantly affected by heat treatment. Fouling development on the ESPA2 membrane was retarded significantly by the heat treatment when the secondary effluent was filtrated at an elevated permeate flux. It is hypothesised that the denser active skin layer of the heat-treated RO membranes may prevent the penetration of low molecular weight organic foulants into the internal structure of the active skin layer. Results reported here suggest that heat treatment can be possibly used to refresh used membranes which usually have decreased salt rejection due to aging and chemical damage. Although heat treatment improved fouling resistance, the impact of heat treatment on the long-term performance and life-time of membranes is still unknown. Thus, further research is necessary to clarify the impact of heat treatment on the integrity and aging of RO membranes. In addition, improving the antifouling characteristics and efficiency of the heat treatment by clarifying the mechanism of heat treatment impact will be beneficial for further economical membrane modification.

\section{Acknowledgements}

The authors acknowledge the University of Wollongong for a PhD scholarship awarded to Takahiro Fujioka. Hydranautics/Nitto Denko is also thanked for the provision of membrane samples. The authors also acknowledge Dr. Michael Higgins (Intelligent Polymer Research Institute, UOW) for his assistance with surface roughness measurement and the Australian National Fabrication Facility (ANFF) for providing the AFM instrumentation.

\section{References}

Bartels C., Wilf M., Casey W. and Campbell J. (2008). New generation of low fouling nanofiltration membranes. Desalination 221(1-3), 158-67.

Bellona C., Drewes J. E., Oelker G., Luna J., Filteau G. and Amy G. (2008). Comparing nanofiltration and reverse osmosis for drinking water augmentation. Journal AWWA 100(9), 102-16. 
Bellona C., Drewes J. E., Xu P. and Amy G. (2004). Factors affecting the rejection of organic solutes during NF/RO treatment - A literature review. Water Research 38(12), 2795809.

Elimelech M. (2006). The global challenge for adequate and safe water. Journal of Water Supply: Research and Technology - Aqua 55(1), 3-10.

Elimelech M., Chen W. H. and Waypa J. J. (1994). Measuring the zeta (electrokinetic) potential of reverse osmosis membranes by a streaming potential analyzer. Desalination 95(3), 269-86.

Fritzmann C., Löwenberg J., Wintgens T. and Melin T. (2007). State-of-the-art of reverse osmosis desalination. Desalination 216(1-3), 1-76.

Fujioka T., Khan S. J., McDonald J. A., Henderson R. K., Poussade Y., Drewes J. E. and Nghiem L. D. (2013). Effects of membrane fouling on N-nitrosamine rejection by nanofiltration and reverse osmosis membranes. Journal of Membrane Science 427(0), 311-9.

Fujioka T., Khan S. J., Poussade Y., Drewes J. E. and Nghiem L. D. (2012). N-nitrosamine removal by reverse osmosis for indirect potable water reuse - A critical review based on observations from laboratory-, pilot- and full-scale studies. Separation and Purification Technology 98(0), 503-15.

Gerard R., Hachisuka H. and Hirose M. (1998). New membrane developments expanding the horizon for the application of reverse osmosis technology. Desalination 119(1-3), 4755.

Henderson R. K., Stuetz R. M. and Khanz S. J. (2010). Demonstrating ultra-filtration and reverse osmosis performance using size exclusion chromatography. Water Science \& Technology 62(12), 2747-53.

Kang G. and Cao Y. (2012). Development of antifouling reverse osmosis membranes for water treatment: A review. Water Research 46(3), 584-600.

Lee K. P., Arnot T. C. and Mattia D. (2011). A review of reverse osmosis membrane materials for desalination-Development to date and future potential. Journal of Membrane Science 370(1-2), 1-22.

Li D. and Wang H. (2010). Recent developments in reverse osmosis desalination membranes. Journal of Materials Chemistry 20(22), 4551-66.

Matin A., Khan Z., Zaidi S. M. J. and Boyce M. C. (2011). Biofouling in reverse osmosis membranes for seawater desalination: Phenomena and prevention. Desalination 281(0), 1-16.

Shintani T., Matsuyama H. and Kurata N. (2009). Effect of heat treatment on performance of chlorine-resistant polyamide reverse osmosis membranes. Desalination 247(1-3), 370-7. 
Tang C. Y., Fu Q. S., Criddle C. S. and Leckie J. O. (2007). Effect of Flux (Transmembrane Pressure) and Membrane Properties on Fouling and Rejection of Reverse Osmosis and Nanofiltration Membranes Treating Perfluorooctane Sulfonate Containing Wastewater. Environmental Science \& Technology 41(6), 2008-14.

Traves W. H., Gardner E. A., Dennien B. and Spiller D. (2008). Towards indirect potable reuse in south east Queensland. Water Science \& Technology 58(1), 153-61.

Vrijenhoek E. M., Hong S. and Elimelech M. (2001). Influence of membrane surface properties on initial rate of colloidal fouling of reverse osmosis and nanofiltration membranes. Journal of Membrane Science 188(1), 115-28.

Wintgens T., Salehi F., Hochstrat R. and Melin T. (2008). Emerging contaminants and treatment options in water recycling for indirect potable use. Water Science \& Technology 57(1), 99-107.

Xu P., Bellona C. and Drewes J. E. (2010). Fouling of nanofiltration and reverse osmosis membranes during municipal wastewater reclamation: Membrane autopsy results from pilot-scale investigations. Journal of Membrane Science 353(1-2), 111-21.

Zou L., Vidalis I., Steele D., Michelmore A., Low S. P. and Verberk J. Q. J. C. (2011). Surface hydrophilic modification of RO membranes by plasma polymerization for low organic fouling. Journal of Membrane Science 369(1-2), 420-8. 
310 LIST OF FIGURES

311 Figure 1: Schematic diagram of the cross flow RO filtration system.

312 Figure 2: Change in (a) pure water permeability and (b) conductivity rejection of the ESPA2 313 membranes after the heat treatment with $70{ }^{\circ} \mathrm{C}$ Milli-Q water for 3, 24 and 72 hours. Pure

314 water permeability was determined with Milli-Q water at $1,000 \mathrm{kPa}$ and $70{ }^{\circ} \mathrm{C}$ feed

315 temperature. Error bars show the standard deviation of three replicate experiments.

316 Figure 3: Conductivity rejection by the ESPA2 membranes as a function of pure water 317 permeability. Experimental conditions are as described in Figure 2.

318 Figure 4: Change in zeta potential of the ESPA2 membranes after the heat treatment with 70

$319{ }^{\circ} \mathrm{C}$ Milli-Q water for 24 and 72 hours. The analysis of zeta potential was carried out in $1 \mathrm{mM}$

$320 \mathrm{KCl}$ solution. Error bars represent the standard deviation of two replicate experiments.

321 Figure 5: FTIR spectra of the ESPA2 membranes with and without heat treatment (24 hours).

322 Figure 6: Fouling development by the virgin and heat-treated (24 hours) membranes using 323 the secondary effluent (Cross flow velocity $0.42 \mathrm{~m} / \mathrm{s}$, feed temperature $20 \pm 0.1{ }^{\circ} \mathrm{C}$, and feed 324 pressure (a) heat-treated membranes $1000 \mathrm{kPa}$ and (b) virgin membranes $700 \mathrm{kPa}$ ). 


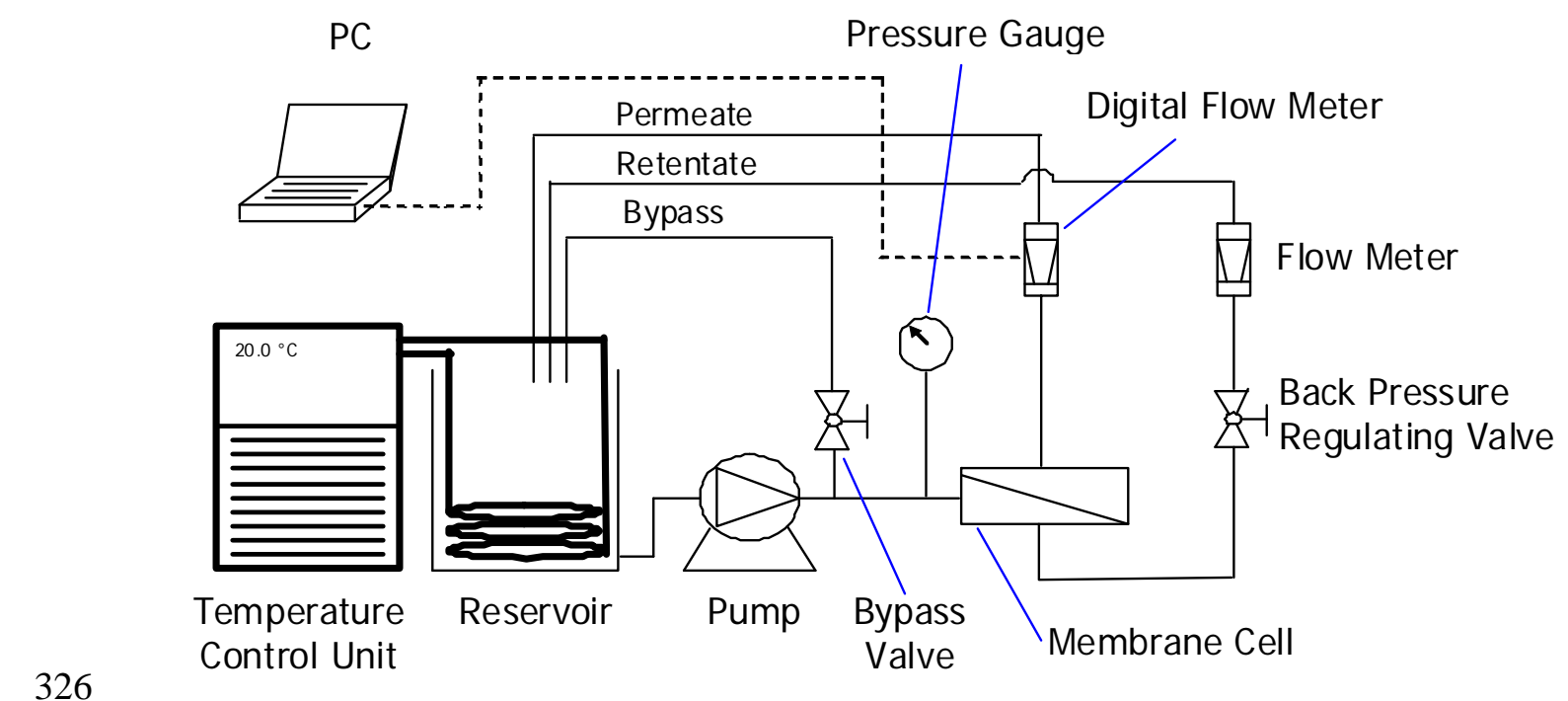

327 Figure 1

328 


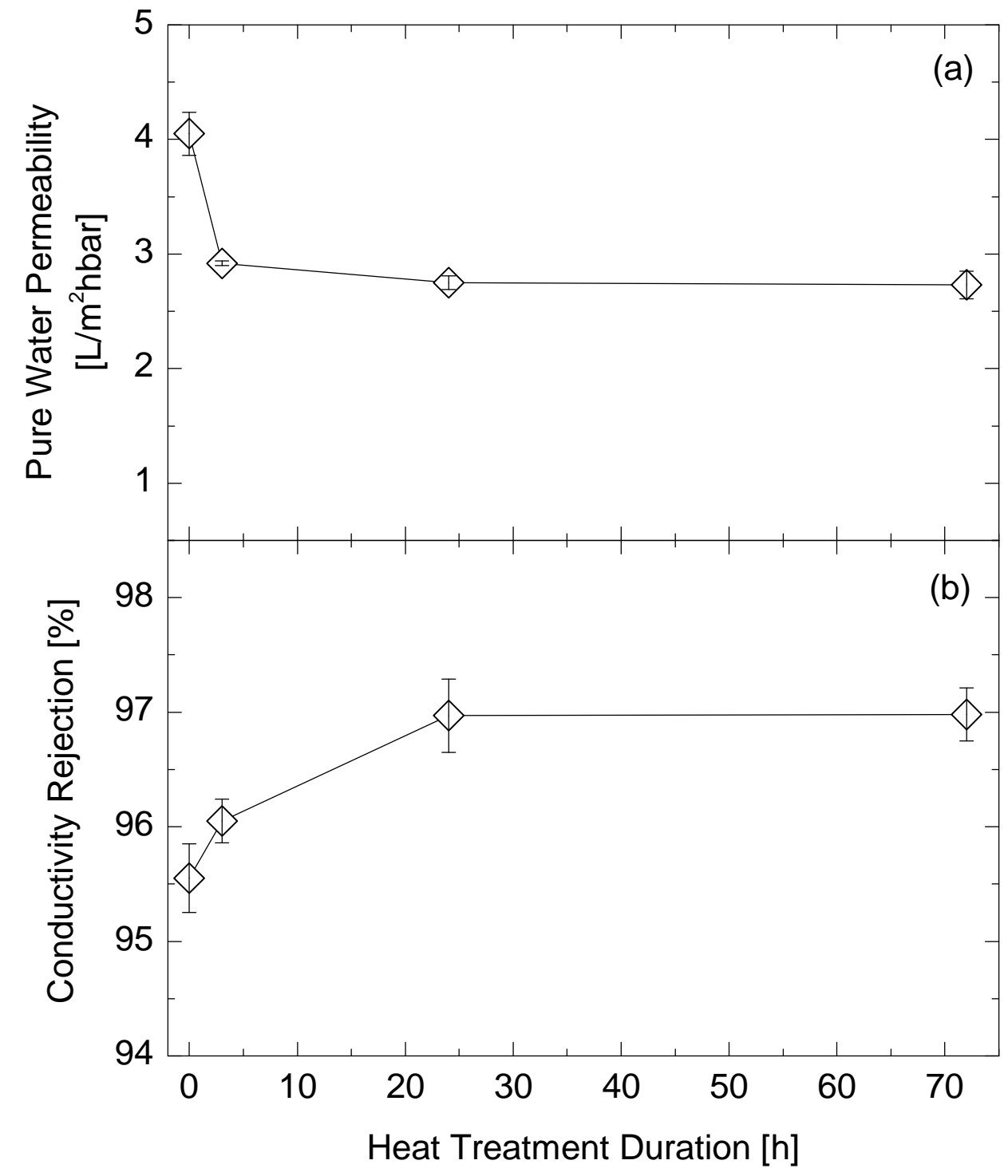

329

330

Figure 2 


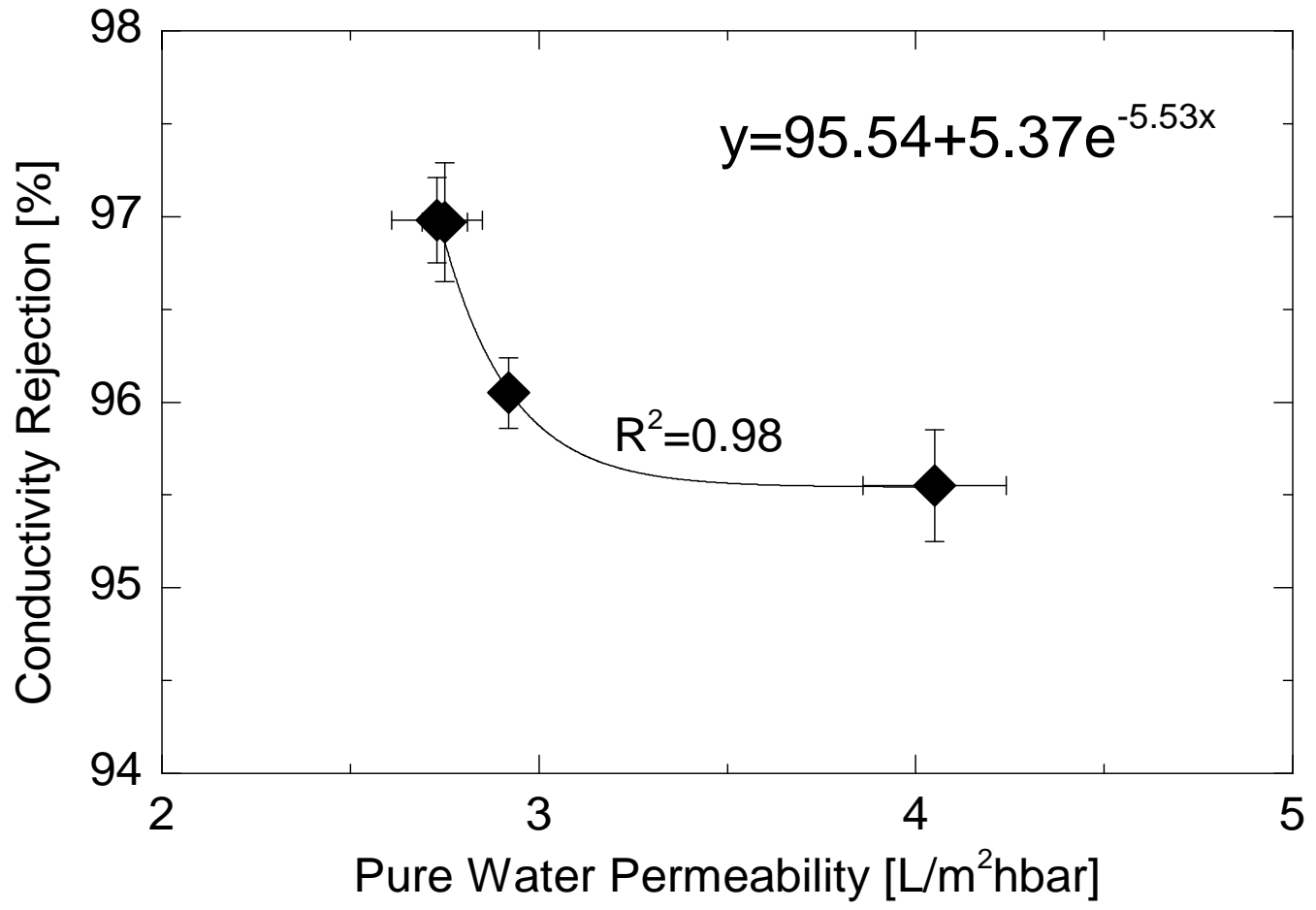

Figure 3 


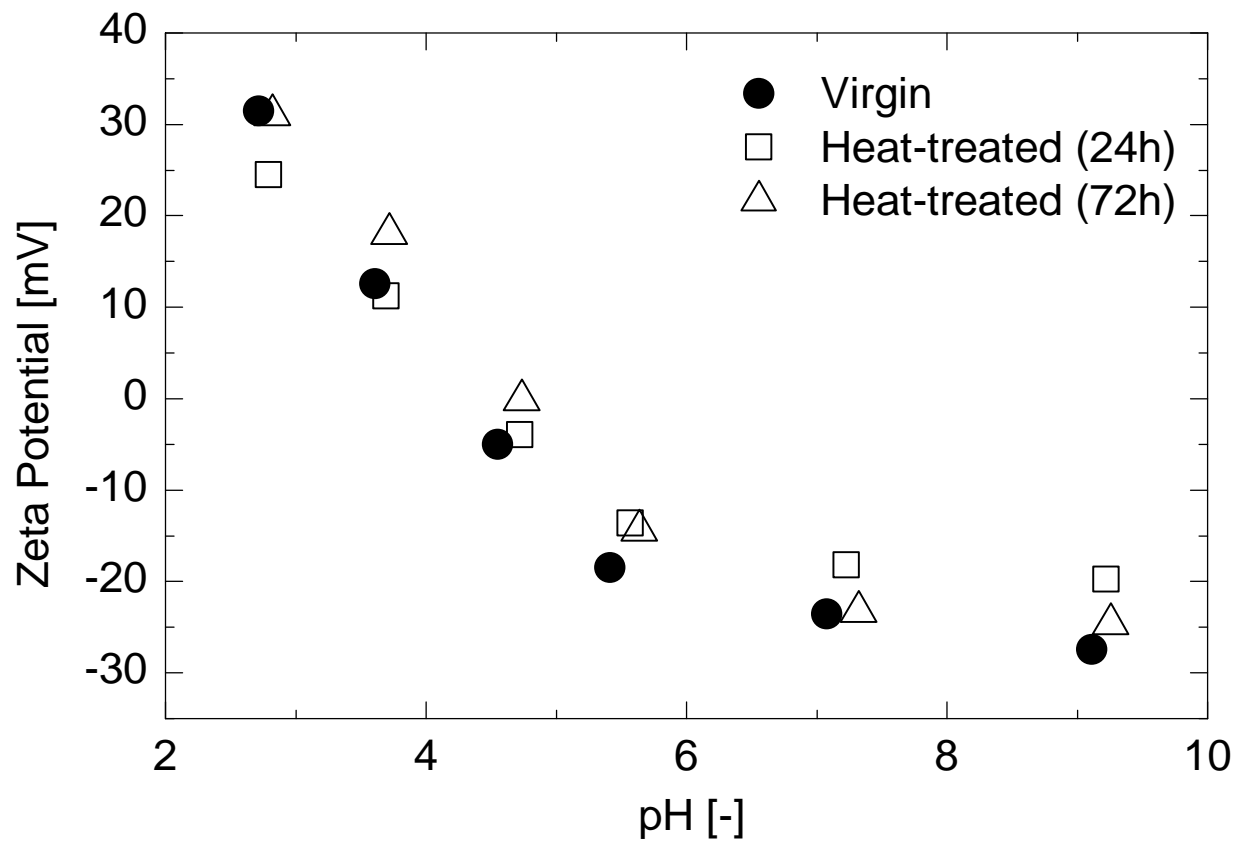

333

334

Figure 4 


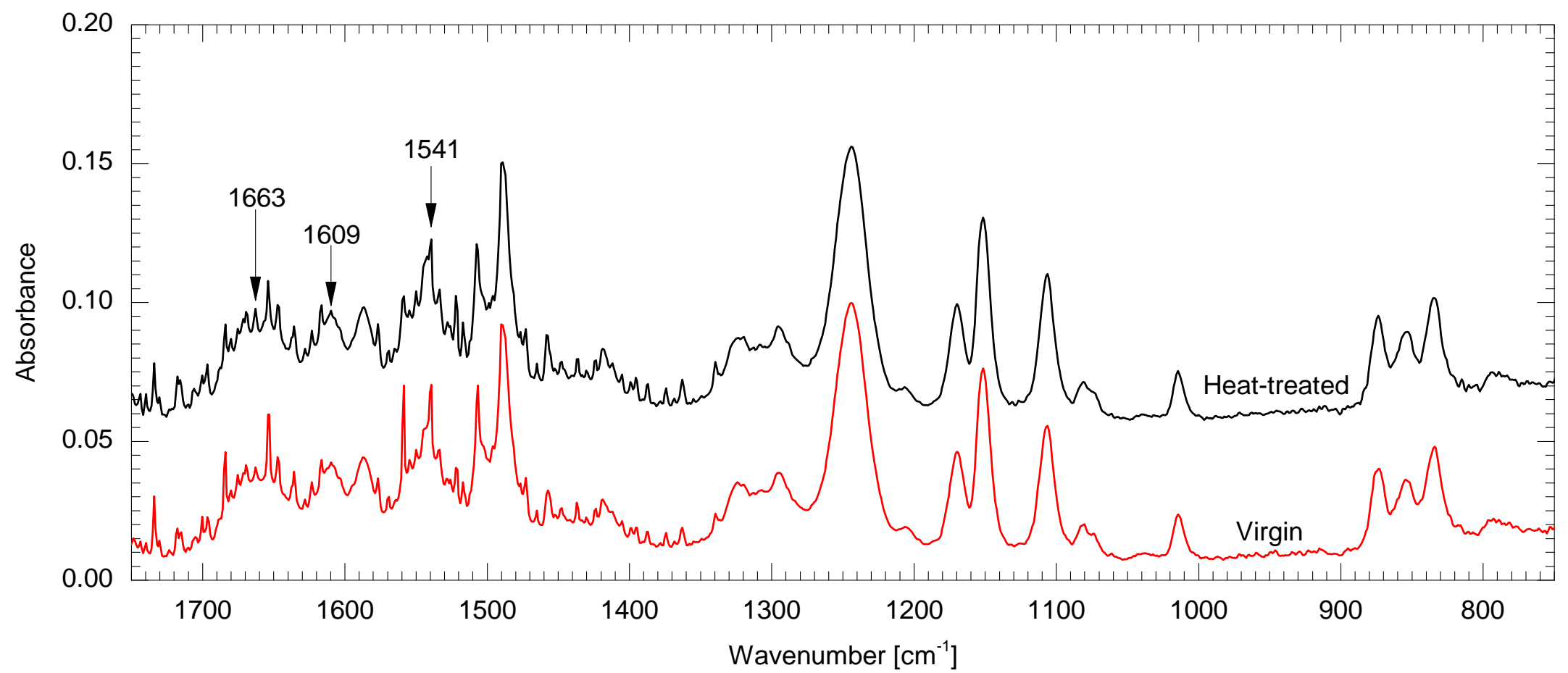

Figure 5 


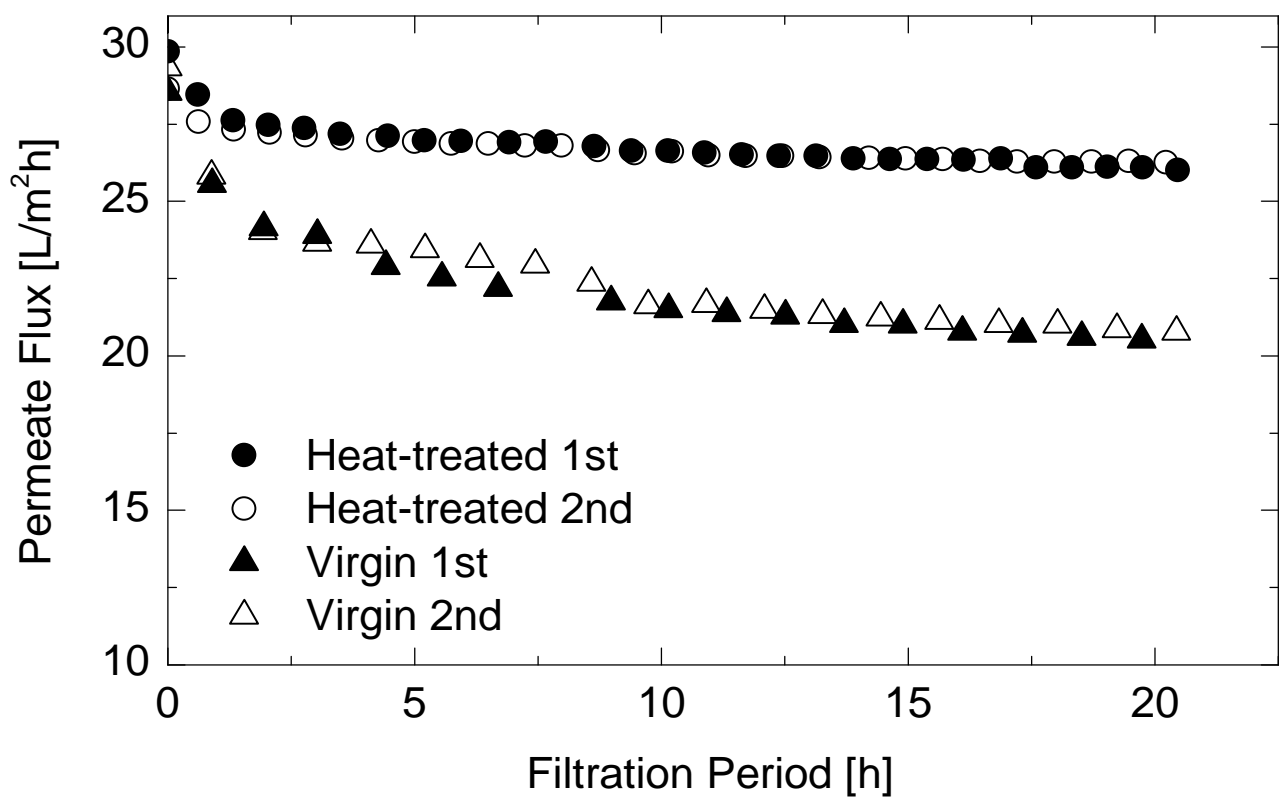

Figure 6 